\title{
DO WE REALLY NEED SIGNS? URBAN WAYSHOWING DESIGNED FROM WITHIN THE SURROUNDINGS
}

\author{
HUSSAH K. ALOTAISHAN \\ School of Art and Design, Cardiff Metropolitan University, United Kingdom
}

\begin{abstract}
Wayshowing can be defined as those designed solutions that help users (wayfinders) to get from their current location to their desired destination within urban settings. Until recently, wayshowing design has always been associated with the more traditional navigation methods such as directional signs and maps. Both tourism and/or globalization have become major elements that affect urban cities and the way they evolve. And with the push to globalize cities, the sensitivity of local identity retention is challenged. The Bristol Legible city project in Bristol, United Kingdom, is an example that demonstrates combining identity-keeping ideology and wayfinding system design. The main purposes of this paper are to: address how urban features may be used as clues to replace the literacy and language dependant wayfinding aids, and minimize their inherent exclusiveness in pedestrian urban settings to offer equal opportunities to people from different cultural background and various spoken languages. The aim is to identify which objects are considered significant enough within the surrounding environments to facilitate the user's getting from one place to another with minimal stress and in the shortest route possible. During this study, I intend to test wayfinder's decisionmaking skills, orientation skills and stress levels in real-life locating task experiments in the city of Swansea, UK, combined with a historical and architectural analysis of the city around the area in which the experiments will take place. The goal of these experiments is to identify to what extent urban features can operate without signage as wayfinding systems in pedestrian settings.

Keywords: pedestrian wayfinding, wayshowing aids, urban environment, cultural differences.
\end{abstract}

\section{INTRODUCTION}

Wayshowing is a fairly new term introduced by Per Mollerup as "the professional activities of Architects and graphic designers that inform wayfinding" [1]. In other words, it is an intentionally designed solution that aims to help the users to get to their desired destination with ease and comfort. Kevin Lynch [2] in his book 'The Image of the City' introduced the term wayfinding as the "consistent use and organization of definite sensory cues from the external environment", which covers the users' multi-sensory process while traveling from a current location to a desired destination. Although these terms are not identical, most current research addressing the area of human navigation uses the term wayfinding for both the user's multi-tasking process and the proposed designs to facilitate it.

Wayshowing design has been associated with the more traditional aiding methods such as directional signs and maps. Both tourism and/or globalization have become major aspect affecting urban areas and the way they evolve. Now with increasing globalisation of cities, the sensitivity of local identity keeping is challenged. Addressing a wider range of users needs while finding their way around is crucial in everyday activities as well as for tourists or first-time visitors to a city in order to ensure that their needs can be met without causing stress or frustration during the process.

Scholars have argued that both environmental characteristics and the user's own mental and physical abilities and mental processing when completing a wayfinding task affect the wayfinding process. While most designed wayshowing solutions are literacy dependant aids or electronical navigational support devices, we argue that it is fundamental to examine the urban environment itself as an information provider as well as a medium in which the 
wayfinding process takes place. There is limited research available that considers the environment itself as an information provider or a communication tool for the wayfinder to use during the process. Although some researches have questioned the effect of elements such as landmarks [3], [4] or floor connectivity [5] and geometry [6] as part of environmental legibility. Therefore, the main purpose of this paper is to: test how urban features can function as wayshowing clues to replace conventional literacy and language dependant wayfinding aids, and so minimize their disadvantages in pedestrian urban settings to provide wider opportunities to people from different cultural backgrounds and overcome language barriers. This study contributes to understanding how the current urban environment feeds the wayfinding process with clues and directions that either help or obstruct the flow of the given task.

This paper is structured as follows. Firstly, it provides an overview of the environmental, psychological and physical factors that have been associated with users' wayfinding strategies and processes. Then it examines spatial perception theory and wayfinding tasks as a methodology in real-life settings. It then outlines the research design and methods applied in this study. Then the study results are demonstrated and discussed. Finally, it presents the conclusion and suggests possible implications within the area of pedestrian wayfinding in urban environments.

\section{LITERATURE REVIEW}

In recent and current literature that addresses the area of human navigation it appears that a number of aspects are always associated with the pedestrian wayfinding process and/or the wayshowing design process. These factors vary depending on how these studies reviewed the issue. However, there are four factors that have been distinctly reported as influential and have direct effect on the overall wayfinding process. These factors are: 1) the culture of the space and its users [7]-[12]. 2) The environment, which consists of many complex characteristics that can be individually focused upon or as a whole. These aspects of the environment have been subjected to test in real-life or using VR technology including; familiarity [13], [14], colour and light [15], spatial configuration [16], layout complexity [5], geometry [6]. The reason behind the focus on outdoor environment is due to the limited research studying these four factors in outdoor settings [13]-[15], [17]. 4) The user wayfinding process strategies [3], [17].

\subsection{Factor 1 - The culture}

Hund et al. [11] concluded that cultural differences affect the wayfinding process through affecting - at the least - the clarity of direction giving in terms of terminology to describe a place and the attempt to reach it. This could be in the form of the various phrases that people use to describe landmarks, cardinal directions and precise destinations like street or district names. Their research showed a difference in methods of usage based on the cultural difference between 2 groups, one in the US and the other in Netherlands. While the former used cardinal descriptions while direction giving, the latter mainly used landmarkbased directions.

\subsection{Factor 2 - The environment}

\subsubsection{Environmental intelligibility}

The users' ability to understand the nature of their surroundings [6] is a strong factor that affects wayfinding processes via both spatial recognition and mental perception. Links to 
safety and comfort are present in most research that addresses human navigation [18], [19]. Many have argued that environment intelligibility directly influences spatial legibility [16]. In particular Mehta [18] links pleasure-ability through the visual comfort of the environment to better support cognitive mapping ability, which leads to better and easier completion of the wayfinding task.

\subsubsection{Environmental legibility}

Physical or visual qualities make elements of the environment easily read and identified from the surroundings [1]. In recent years, there has been an increasing interest in investigating the correlation between the geometry and the level of legibility in urban environments. Lynch [2] argued that well-structured and legible environments would lead to better mental mapping abilities with users in unfamiliar environments. He also defined environment legibility through obtaining 3 qualities: clarity, visibility and coherence. Later Weisman [13] narrowed the characteristics of what he called "good form" or legible environment, to 3 elements: symmetry, regularity and continuity. Mahdzar and Safari's [6] research on the city of Kuala, Kuala Lumpur, Malaysia supports Lynch's theory of the importance of environment legibility on human wayfinding ability. However, they and others like Conroy-Dalton and Bafna [20] argue that cognitive maps are operated in a hierarchical order, where once spatial configuration has been acquired the cognitive map may then be elaborated by adding visual elements from the surroundings. But unlike Lynch's theory they suggest that spatial elements have a more dominant role in the process of cognitive mapping than visual elements, the basis for Lynch's human perception logic in the context of wayfinding.

However, Mahdzar and Safari [6] focused their research on spatial 2-dimensional configuration because they claim that buildings and activities occupying modern city centres have not enough distinctive $3 \mathrm{D}$ characteristics to facilitate the environment to be more legible. But Slone et al. [5] could not rule out the effect of landmark visual features on participant cognitive mapping. Instead, they suggested that their saliency could be a variable factor in future wayfinding experiments to measure their effect. Hund [17] adds that fewer elements or details to remember leads to faster visuospatial memory processing while the users find their way around. Consequently, both visual elements within the surroundings and the spatial layout could affect the wayfinding process, and the question is to what level could they influence the process? And how can we implement this information to best serve the needs of the wayfinder?

\subsection{Factor 3 - The wayfinding process and strategies}

The wayfinding process consists of two main parts: the mental process and the physical act [14]. First is the mental process or what can be called acquisition of special knowledge through processing the information presented by the surroundings, which vary from one individual to another in term of their perception and cognition abilities. Second are those physical actions that get the user from their current location to their desired destination, commonly known as the theory of locomotion.

\subsubsection{Information processing}

Hunter et al. [1] broke down the process into steps that may be condensed to 5 steps: 1) Grouping information into categories for better spatial memorizing. 2) Breaking down the wayfinding task into shorter goals that form a network of nodes - like getting to the corner of the green building. 3) Reducing cognitive load by selectively identifying codes within 
the environment like street name or building number. 4) Mentally mapping the routes into shorter segments of start and end nodes regardless of those in between. 5) Memorizing the passing scene to recognize the return route. Hund [17] examined the role of working memory during the process of wayfinding and he argues that both verbal and visuospatial aspects of the working memory are involved in learning, recognizing and recreating routes. He found that people tend to recall visual and spatial clues when asked about directions. This is supported by Holscher et al. (cited in Hund, [17]) who concluded that the visuospatial part of the working memory is more important for generating accurate wayfinding direction than verbal tasks. Therefore, testing the level of impact of visual elements within the surroundings on the wayfinding process could help to better understand how can we improve the urban space and help the users to have a positive experience.

\subsubsection{Perceptual processing}

Many theories have strongly linked spatial perception with the cultural background of the user. Cullen [7] in his book The Concise Townscape explained the theory through exploring different scenarios. He called it the functional tradition theory, which addresses the fact that the long-term users of a space tend to develop an unspoken language that could be very hard to understand for an outsider or a first-time user. This includes simple everyday acts such as the call to prayer in Saudi Arabia that means shops and restaurants will close soon until the prayer finishes. Or when the bartender calls last orders, only people used to going to pubs know that this substitutes for a "we are about to close" sign. Additionally, recent studies on spatial perception in urban spaces links the ease of the process to three elements. 1) Better compatibility between a space and the activities happening in it. 2) The level of legibility. 3) The amount of perception produced by the environment's visual characteristics [6].

\subsubsection{Spatial cognition}

Lynch [2] explained that people perceive their landscape through 5 elements: nodes, path, district, landmark and edge. Mahdzar and Safari [6] adds that the first 3 are topological because they facilitate users to anchor their location. The edge and landmark particularly may have complex geometric features that enable them to provide information on both distance and direction. Many recent researchers argue that spatial cognition should be considered as a dual task condition strongly connected to the physical movement aspect of the wayfinding process [1]. In other words, the mental load during the wayfinding process is not focusing merely on understanding and learning what the environment has to offer, but also on learning how to use the acquired information to physically move from the current location to the next desired destination. This theory indicates that wayfinding experiments should include physical actions when studying spatial cognition.

\subsubsection{Locomotion}

Locomotion is a phrase that refers to any type of movement, but for the purpose of this research, the phrase will be used to describe human walking action. Understanding the physical process of wayfinding is a crucial aspect that designers need to investigate before attempting to design a wayshowing scheme [1], [21]. Li and Klippel [14] argued that the performance of wayfinding consists of spatial knowledge and locomotion, where the latter mainly measures the travel time and the length of the travel route. On the other hand, Walkability is a term to describe the environment's own quality that have direct impact on users' walking behaviour. Urbanists Jane Jacob and William H Whyte strongly argued for the impact of walk-able cities and the important role played by street culture on the quality of 
social life and health of the users [9], [12]. Furthermore, in linking the visual and the physical aspects, Cullen [7] mentioned a 'co-serial vision' [or the 'ambient optic array' as Gibson [22] called it in his book The Ecological Approach to Visual Perception]. A serial vision while the user is in motion consists of a series of emerging images replacing an existing one. For example, this is like video photography broken down to a series of frames. The importance of this concept to this research relies on how what the user considers as significant elements within the environment are introduced to the wayfinder within the overall view. This may help to better understand to what extent "landmarks" or focal points may have a noticeable impact on the user's wayfinding process.

\section{THEORY AND PRACTICE}

The study of wayshowing design and wayfinding strategies and process is rooted in the theory of spatial perception and spatial cognition [1]. These theories have been recently strongly connected to the neuro-motor controls responsible for physical actions such as walking, cycling or swimming. In other words, the complexity of a wayfinding process includes perceiving new environments, or using previously acquired environmental knowledge, known as the familiarity factor. The other part of the wayfinding process is described by the theory of locomotion, which argued that the mental processing for a space while attempting to find a destination is partially dedicated to physical decision-making on how to move.

A better understanding of human mental processing while finding their way around could be accomplished when two theories are combined: Lynch's [2] environmental image ability theory and Gibson's [22] affordance theory. Lynch's theory attempts to examine the role of environmental images on urban daily activities and took place in three cities: Boston, Jersey City and Los Angeles. His research identified what is now widely known as the five elements of environment, which are paths, nodes, edges, districts and landmarks. Gibson's theory on the other hand aims to go beyond the visual aspect of the environment, being concerned in addressing what each element within the physical environment can afford to provide, for example the paved street that affords stability so that walking is possible.

This study aims to: One - record and analyze how the urban layout of Swansea, UK affects the wayfinding process of first time visitors trying to locate several places, without using navigational tools like Google maps, or following the signs provided as part of the city's current wayfinding scheme. Two - implement Lynch's [2] classification to identify how the wayfinder's decisions are made when facing elements like node, edges or landmark. Three - use Gibson's [22] affordance theory to help understand the messages Swansea's current layout and urban design is sending in the context of pedestrian navigation.

\section{RESEARCH DESIGN AND METHODOLOGY}

\subsection{Research design}

The initial study is an experimental research design that took place in the city of Swansea, UK by asking the participant to attempt to locate 9 attraction zones available around the city centre that either identified as recreational, commercial or tourist attractions. These 9 places, which are 1) Swansea Market, 2) St. Mary's Church, 3) Swansea Castle, 4) Swansea Museum, 5) The National Water Front Museum, 6) The Attic Gallery, 7) The Sail Bridge, 8) The Norwegian Church, 9) Dylan Thomas Centre, were introduced to the participant by pictures provided on A4 two-sided sheet (Fig. 1) as their only clue and they were asked to 
keep it and look at it whenever they want. The places were numbered from 1 to 9 but the participants were briefed that the numbers should not restrict them and that it was provided as a clue when needed, for example: Picture 7 the Sail Bridge is geographically important to locate picture 8 The Norwegian Church and therefore they were numbered accordingly.

The process of choosing the locations was part of an earlier ethnographical experiment in the unfamiliar city made by the researcher one month in advance that concluded what places should be included or excluded in conjunction with the time limits and ease of the experiment. For example, Plantasia is an attraction point that is advertised by the Swansea tourist list as a must visit however, due to the location of the place outside the centre of the city with no easy walk-able access with a clear visual path, it had to be excluded. On the other hand, although The Norwegian Church is located across the Sail Bridge, the aim of including it was to identify the impact of the surroundings as environmental clues during the wayfinding process. In this particular case, the Sail Bridge and a glass building façade visible in the background of the provided picture were under investigation to record if they could provide enough information to facilitate the participant to complete the task in hand.

The Experiment routes (Fig. 2) started at the Swansea train station and were scheduled not to exceed one-and-a-half-hours. Each participant had freedom to decide which direction to go and what route to take. A thinking aloud method was encouraged, and, while the researcher accompanied each participant throughout the task, open-ended questions were posed at decision points and/or when the participant seemed confused.

\subsection{Initial study participants}

Four Saudi Arabic-native Female postgraduate students living in Cardiff participated in the study. The recruiting needed to be as narrow as possible to eliminate any differences that could affect the wayfinding strategies and process. Therefore, all four participants were non-drivers, aged between 20 and 30 years old and had lived in Wales for a minimum of 5 months. The females were interviewed prior the beginning of the task locating experiment and a personal profile (Table 1) list was completed together with a complete description of the task in hand and finally the consent forms were signed. The interview revealed that all the participants tend to use Google Maps as the preferable navigational tool. It is noted that although the number of participant cannot validate the findings, the narrow scope forced the study to be limited due financial restrictions and the difficulty of finding participants that fall under the assigned characteristics.

\subsection{Data collection and experiment procedure}

Data for this study was obtained via the use of a Heart rate monitoring device, plus thinking aloud methodology while wayfinding, as well as the completion of The Positive and Negative Affect Schedule twice, ones prior to starting the experiment and ones just after completing the tasks. This questionnaire was utilized because pleasure-ability is a quality that has been strongly connected to the ease and comfort of the wayfinding process [18]. Before the start of the experiment, each participant was given a Mio FUSE watch to wear during the experiment to monitor her heart rates. Connected to a MapMyRun app that was running on an I-Phone 7 carried by the researcher, which was also used to take photos when needed as well as tracking the movement of the participant. The researcher carried out the physical data collection for 4 days, traveling every day from Cardiff to Swansea with each participant one day at a time in March 2017. 


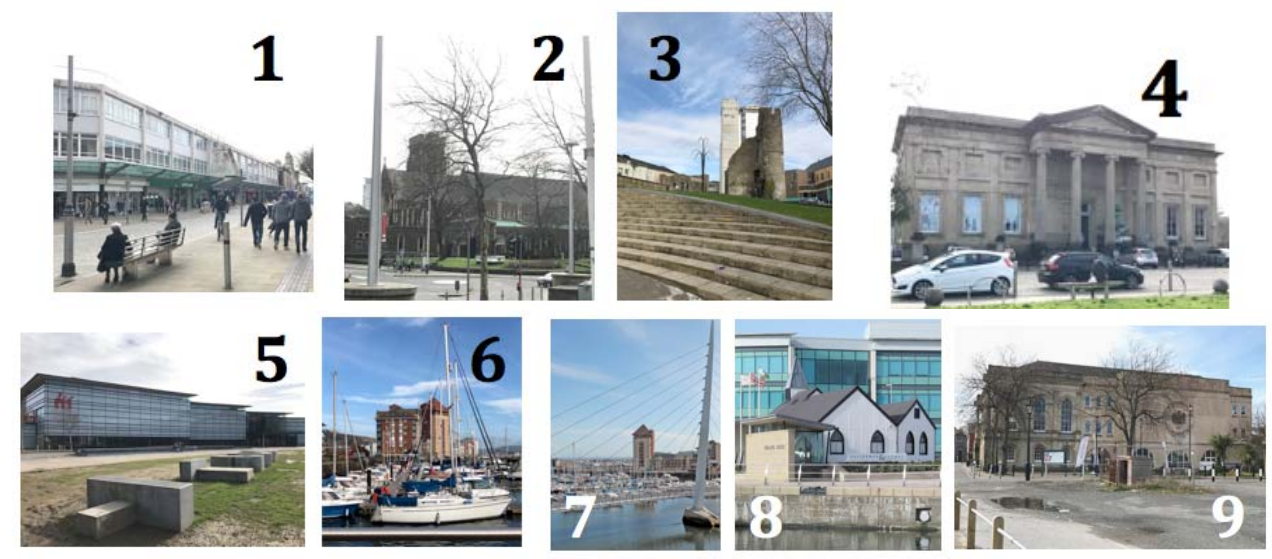

Figure 1: The pictured clues numbered and handed to the participant's prior the start of the experiment [23], [24].

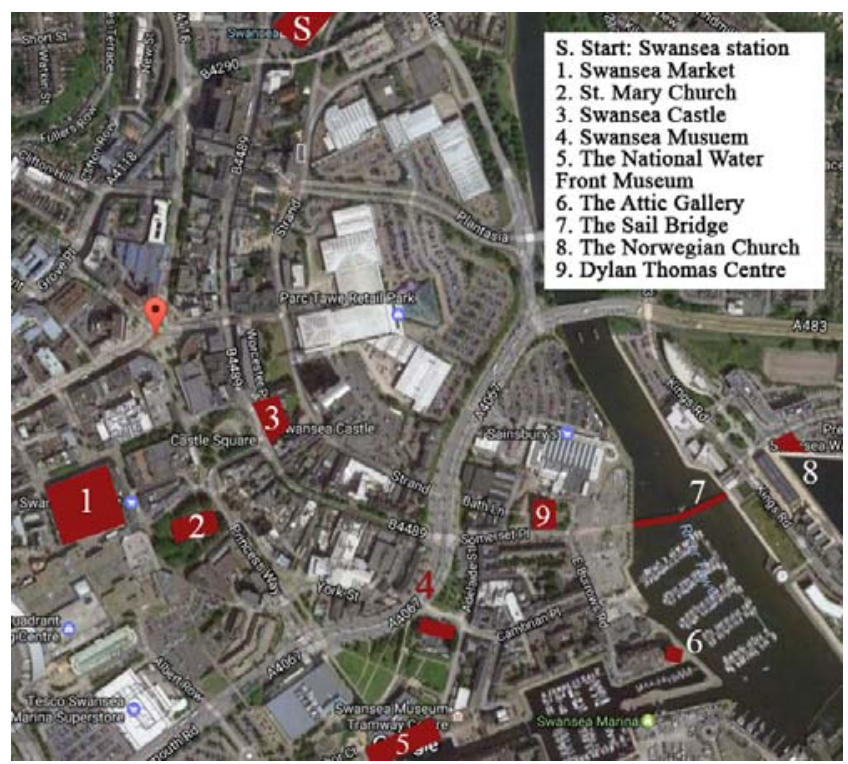

Figure 2: The 9 places on the locating task list highlighted on Swansea City Centre Map.

Table 1: Participant personal profile.

\begin{tabular}{|c|c|c|c|c|c|}
\hline Participant & Age & $\begin{array}{c}\text { Native } \\
\text { Language }\end{array}$ & $\begin{array}{c}\text { English } \\
\text { level }\end{array}$ & Preferred Navigation aid & $\begin{array}{c}\text { Fitness } \\
\text { level }\end{array}$ \\
\hline User 1 & 26 & Arabic & 3 & Friends / Google map & 5 \\
\hline User 2 & 20 & Arabic & 5 & Google map / Ask for direction & 2 \\
\hline User 3 & 24 & Arabic & 3 & Google map / Call for direction & 3 \\
\hline User 4 & 25 & Arabic & 3.5 & Google map/ given direction & 3 \\
\hline
\end{tabular}




\subsection{Data analysis}

First a scoring of the personal profile (Table 1) and PANAS questionnaire (Table 2) was calculated but the readings did not have sufficient evidence to support the theory.

Route tracking maps (Fig. 3) and the acquired verbal data from the open-ended questions and thinking aloud were manually analysed individually by applying Lynch's and Gibson's theory when applicable (Fig. 4). This analytical method aimed to detect a pattern of similarity in processing method or decision making among the users during the duration of the experiment.

The analysis included the following steps. First the 9 zones were marked down and the walking route made by each user from start to end. Then, making a detailed classification of the path using Lynch's environment 5 elements. Followed by locating Gibson's affordance qualities through the user's decisions during task. Furthermore, each place the user finds is recorded with a photograph and an answer for why was this place found. Finally, a documented record of any misleading clues the user might have faced during the task.

\section{RESULT AND DISCUSSION}

This study based on the findings of the small pilot study that have been conducted, although the participants were all Saudi females aged between 20 and 30 that have no driving skills and have been living in the UK for a period no less than 6 months. The spatial cognition

Table 2: The PANAS chart.
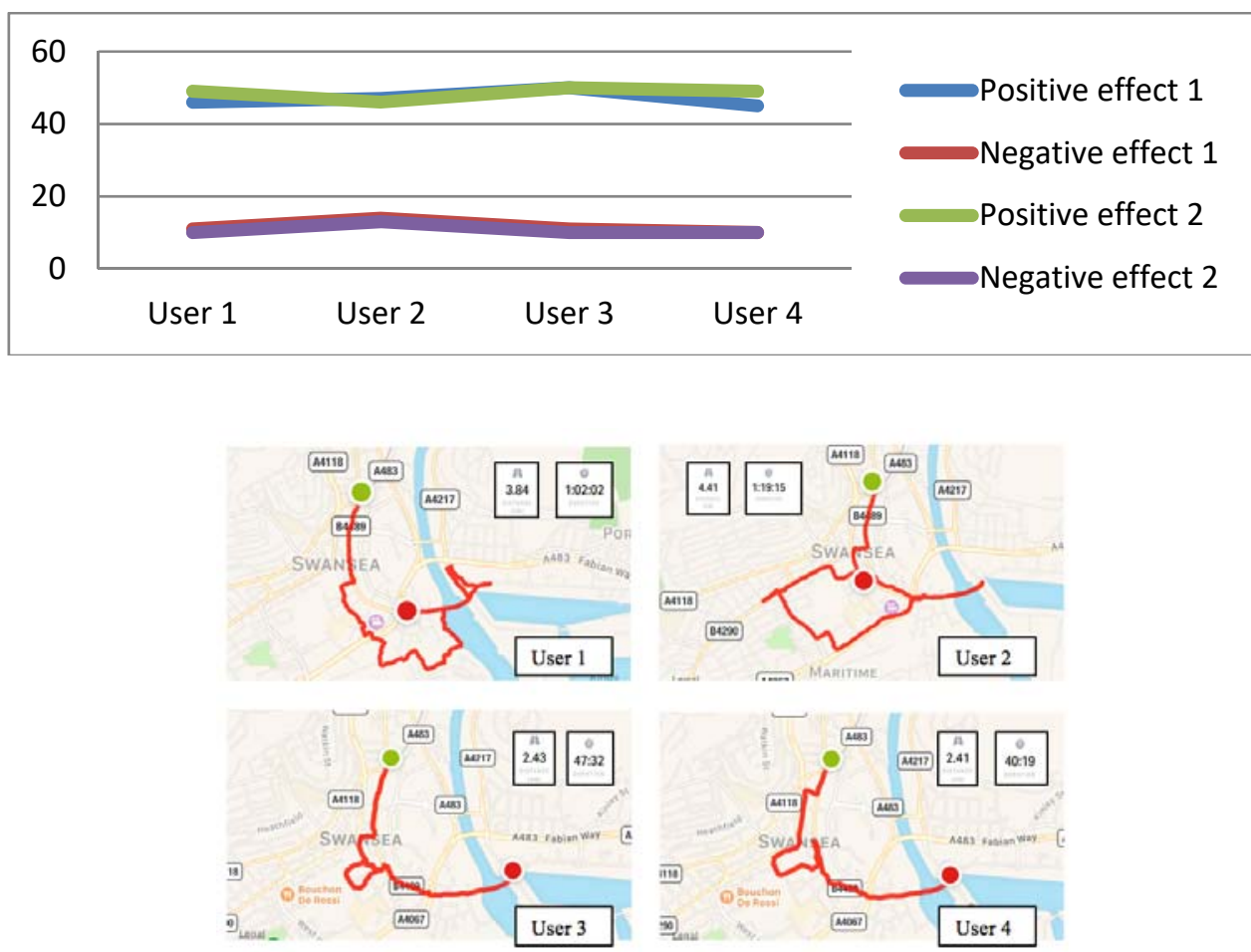

Figure 3: Users' movement route from start to finish. 


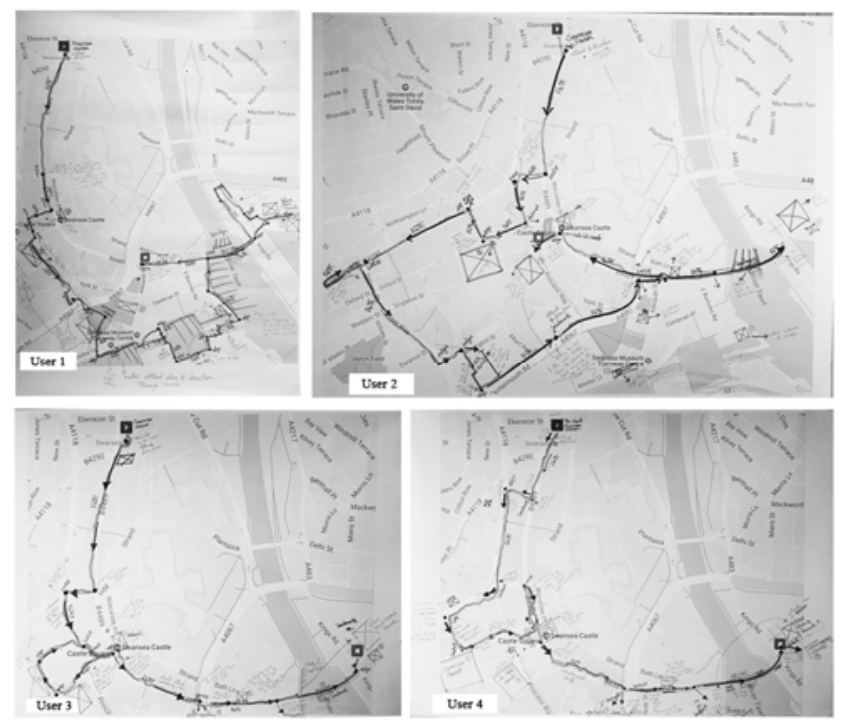

Figure 4: Users' wayfinding process and decision-making analysis.

that fed the wayfinding strategy varied (Table 3), while the majority of the participant walked with the flow of people to the city centre, there was two cases that deliberately walked away from the city centre because, to them, it's associated with shopping and leisure rather than recreational activities. This sort of logical thinking could be influenced by the concept of necessity that Gehl [10] argued it's importance for years and how it can if implemented correctly - improve the quality of life. Also the familiarity aspect of cognitive mapping where the human mind categorizes environment based on similarity of functions, shapes or previous knowledge was supported in this study and in previous ones [13], [14]. Knowing that the study won't support any significant findings due to the limited number of participants, it in fact addresses the importance of the cultural factor to this research project not to be neglected in future studies.

When investigating environment intelligibility and legibility, the ease of visual representation should not be mistaken with simplicity. Complex environment can be as comfortable as a space with minimal visual design if aspect such as geometry, rhythm and connectivity is present (Slone et al. [5]). The theory has been supported by wayfinding studies such as Mahdzar and Safari's [6] findings that strongly associated geometry with legibility due to it facilitates mental mapping process. This claim was communicated by this study through the movement of users although walking by foot with the flow of traffic movements. The users gave reasons to their decision when asked about it by associating it with logical guidance or suggested flow that they felt was intentional and therefore should lead to significantly important part of the city. On the other hand, some nodes or decision points (Fig. 5(a)) were confusing and gave the uses no direction of where to head next. In this case, the users had to assess elements from each side and go with the side that had more potential. Clues where about what the environment have to afford like bigger street, squares or even the height of buildings, combined created interest towards the side that offered more sense of busyness. 
Table 3: Clues and identifications communicated by the users during the task.

\begin{tabular}{|c|c|c|c|c|c|c|c|c|c|c|c|}
\hline & $\begin{array}{l}\text { Swansea } \\
\text { station }\end{array}$ & $\begin{array}{l}\text { Intersecti } \\
\text { on }\end{array}$ & $\begin{array}{l}\text { Swansea } \\
\text { Market }\end{array}$ & $\begin{array}{l}\text { st mary } \\
\text { church }\end{array}$ & $\begin{array}{l}\text { Swansea } \\
\text { Castle }\end{array}$ & $\begin{array}{l}\text { Swansea } \\
\text { Museum }\end{array}$ & $\begin{array}{l}\text { Water } \\
\text { Front } \\
\text { Museum }\end{array}$ & $\begin{array}{l}\text { Attic } \\
\text { Gallery }\end{array}$ & $\begin{array}{l}\text { Sail } \\
\text { Bridge }\end{array}$ & $\begin{array}{l}\text { Norwegia } \\
\text { n Church }\end{array}$ & $\begin{array}{l}\text { Dylan } \\
\text { Thomas } \\
\text { Centre }\end{array}$ \\
\hline $\begin{array}{l}\overline{5} \\
\stackrel{\Xi}{د}\end{array}$ & $\begin{array}{l}\text { Follow the } \\
\text { people }\end{array}$ & $\begin{array}{l}\text { Street lights } \\
\text { tills her it's } \\
\text { the city } \\
\text { centre }\end{array}$ & $\begin{array}{l}\text { The blue } \\
\text { sign across } \\
\text { the street }\end{array}$ & $\begin{array}{l}\text { The green } \\
\text { glass shade }\end{array}$ & The layout & $\begin{array}{l}\text { The colour } \\
\text { of the stone } \\
\text { and the } \\
\text { façade }\end{array}$ & $\begin{array}{l}\text { The glass } \\
\text { facade }\end{array}$ & $\begin{array}{l}\text { The boats, } \\
\text { The colours } \\
\text { Building } \\
\text { layout }\end{array}$ & $\begin{array}{l}\text { Misleading } \\
\text { around the } \\
\text { masts }\end{array}$ & \multirow{4}{*}{$\begin{array}{l}\text { The clue } \\
\text { leading to it } \\
\text { is the } \\
\text { blue/green } \\
\text { glass façade } \\
\text { of the } \\
\text { building } \\
\text { behind it. } \\
\text { When } \\
\text { arriving to } \\
\text { the } \\
\text { destination, } \\
\text { the church } \\
\text { is visible. }\end{array}$} & $\begin{array}{l}\text { Window } \\
\text { layout and } \\
\text { logo }\end{array}$ \\
\hline 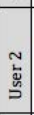 & $\begin{array}{l}\text { Follow } \\
\text { busier } \\
\text { side. The } \\
\text { other side } \\
\text { residential }\end{array}$ & $\begin{array}{l}\text { Looks } \\
\text { busier. Gym } \\
\text { and shops } \\
\text { means the } \\
\text { centre }\end{array}$ & $\begin{array}{l}\text { The corner } \\
\text { shop white } \\
\text { sign }\end{array}$ & $\begin{array}{l}\text { Surroundin } \\
\text { g landscape } \\
\text { fixtures } \\
\text { and glass } \\
\text { roof }\end{array}$ & $\begin{array}{l}\text { The steps } \\
\text { of the } \\
\text { square and } \\
\text { the layout }\end{array}$ & $\begin{array}{l}\text { One central } \\
\text { door and } 4 \\
\text { columns }\end{array}$ & $\begin{array}{l}\text { The logo } \\
\text { then the } \\
\text { glass facade }\end{array}$ & $\begin{array}{l}\text { The Pier, } \\
\text { The colours } \\
\text { Building } \\
\text { layout }\end{array}$ & $\begin{array}{l}\text { Seen from } \\
\text { distance } \\
\text { due to } \\
\text { height }\end{array}$ & & Logo \\
\hline $\begin{array}{l}m \\
\vdots \\
\vdots \\
\end{array}$ & $\begin{array}{l}\text { The door } \\
\text { sends her } \\
\text { to this } \\
\text { way }\end{array}$ & $\begin{array}{l}\text { Busier } \\
\text { looks more } \\
\text { important }\end{array}$ & $\begin{array}{l}\text { The } \\
\text { green/blue } \\
\text { glass } \\
\text { shades and } \\
\text { flag }\end{array}$ & $\begin{array}{l}\text { The shape } \\
\text { of the } \\
\text { building }\end{array}$ & The layout & $\begin{array}{l}\text { The } \\
\text { columns }\end{array}$ & \multirow{2}{*}{ The logo } & $\begin{array}{l}\text { The } \\
\text { Pyramid } \\
\text { rooftop }\end{array}$ & $\begin{array}{l}\text { Recognized } \\
\text { by the } \\
\text { design }\end{array}$ & & \multirow{2}{*}{$\begin{array}{l}\text { Recognized } \\
\text { the rare of } \\
\text { the building } \\
\text { from the } \\
\text { windows }\end{array}$} \\
\hline $\begin{array}{l}+ \\
\dot{5} \\
\stackrel{\Delta}{د}\end{array}$ & $\begin{array}{l}\text { Entrance } \\
\text { sends her } \\
\text { this way }\end{array}$ & $\begin{array}{l}\text { Follow } \\
\text { clock tower } \\
\text { then church } \\
\text { then the } \\
\text { market }\end{array}$ & $\begin{array}{l}\text { The second } \\
\text { floor } \\
\text { window of } \\
\text { the market }\end{array}$ & $\begin{array}{l}\text { The green } \\
\text { landscape } \\
\text { and the } \\
\text { fixtures } \\
\text { around }\end{array}$ & $\begin{array}{l}\text { The steps } \\
\text { of the } \\
\text { square and } \\
\text { the layout }\end{array}$ & $\begin{array}{l}\text { The } \\
\text { landscape } \\
\text { and the } \\
\text { column }\end{array}$ & & $\begin{array}{l}\text { The layout } \\
\text { specially } \\
\text { wall recess }\end{array}$ & $\begin{array}{l}\text { Seen from } \\
\text { distance } \\
\text { due to } \\
\text { height }\end{array}$ & & \\
\hline
\end{tabular}

Poor configuration of the space has been liked to poor connectivity that limits the logical thinking [6], [16]. On the other hand, even if the space is open with no edges that user can relay on as a guide, distinctive landmarks help wayfinder make a decision. For example during the experiment the Norwegian Church was visually hidden therefore, to inform the participant on its location the sail bridge was presented as a directional clue. However, a blue-shade glass building that can be seen from the picture they were given guided all participants towards the church (Fig. 5(b)).

Similarities were easier to detect in some zones than others in wayfinding strategies and decision-making among the users. For example, all 4 users head the same direction getting out of the station (Fig. 5(c)), their communicated reasons varied but a closer look into their response in relation to the surroundings show that this decision is affected by station entrance angle. The entrance layout provided guidance, for the first-time users towards the city center despite the geographical distance, one example for applying Gibson's theory.

\section{CONCLUSION AND FUTURE WORK}

The introduction of smart devices as navigational tools such as Google map or What3words app in everyday wayfinding task has been raising good reviews. However, their functionality can be easily challenged by lack of Internet connection or running out of battery. Therefore, it is as important to address improving the environment itself to achieve a better wayfinding process.
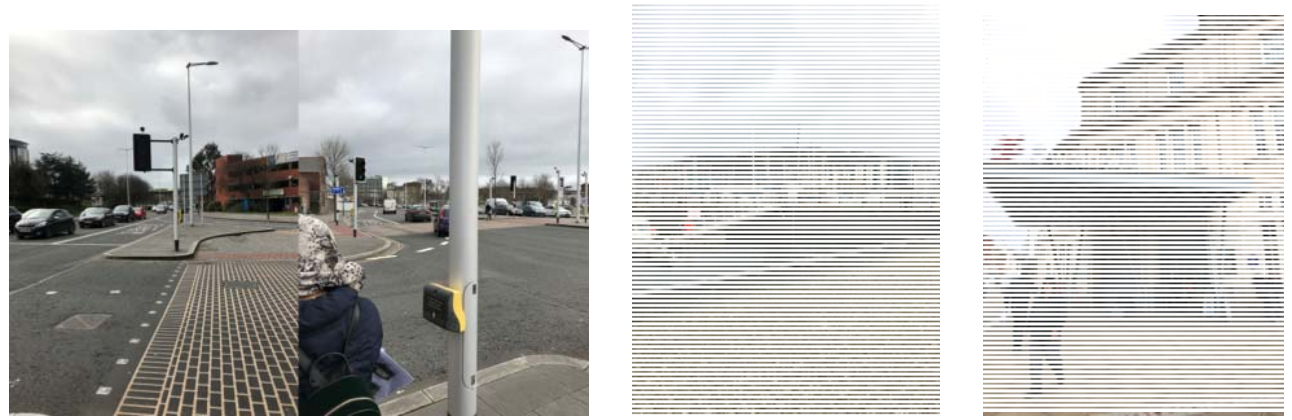

Figure 5: (a) Sides of one decision point; (b) The glass façade clue; (c) The station entrance. 
Landmark recognition is on top of the list when discussing human navigation especially in urban settings. Landmarks with other aspect of the environment such as spatial layout, path connectivity and spatial configuration have been identified as influential on both the cognition and physical process. Whereby this project supports such theories, it aims to take a step further in the future to ensure that the acquired knowledge have evidence-based to support their clam. This paper's experiment will be continued in the near future with bigger number of participant and some changes that needs to be done other than expanding the range of users as well as implementing different emotion measurement tools such as Santa Barbra Sense-Of-Direction Scale, which is more suitable within the context of human navigation than the PANAS questionnaire was. Likewise, the field of pedestrian wayshowing design would benefit from other studies in different settings or facing different challenges like traffic or limited walkability features to better understand what changes should be encouraged to enhance the wayfinder's experience.

\section{ACKNOWLEDGEMENTS}

This research was supported by Imam Abdulrahman Alfaisal University, Dammam, KSA as part of sponsoring the $\mathrm{PhD}$ course. A special thank you to John Counsell the director of studies and to Gareth Loudon and Deiniol Skillicorn for their continuous support and helpful insights. Although they have greatly facilitated the progress of this research, they have no influence on the findings/conclusions of this paper.

\section{REFERENCES}

[1] Hunter, R.H., Anderson, L.A. \& Belza, B.L., Community Wayfinding: Pathways to Understanding, Springer, 2016.

[2] Lynch, K., The image of the city, 11, MIT press, 1960.

[3] Roger, M., Bonnardel, N. \& Le Bigot, L., Landmarks' use in speech map navigation tasks. Journal of Environmental Psychology, 31(2), pp. 192-199, 2011.

[4] Fang, Z., Li, Q., Zhang, X. \& Shaw, S.L., A GIS data model for landmark-based pedestrian navigation. International Journal of Geographical Information Science, 26(5), pp. 817-838, 2012.

[5] Slone, E., Burles, F., Robinson, K., Levy, R.M. \& Iaria, G., Floor plan connectivity influences wayfinding performance in virtual environments. Environment and Behavior, 47(9), pp. 1024-1053, 2015.

[6] Mahdzar, S.S.S. \& Safari, H., Legibility as a Result of Geometry Space: Analyzing and Comparing Hypothetical Model and Existing Space by Space Syntax. Life Science Journal, 11(8), 2014.

[7] Cullen, G., The concise townscape, Routledge, 1971.

[8] Kostof, S., The city shaped: Urban patterns and meanings through history, Thames and Hudson, 1991.

[9] Low, S.M. ed., Theorizing the city: the new urban anthropology reader, Rutgers University Press, 1999.

[10] Gehl, J., Life between buildings: using public space, Island Press, 2011.

[11] Hund, A.M., Schmettow, M. \& Noordzij, M.L., The impact of culture and recipient perspective on direction giving in the service of wayfinding. Journal of environmental psychology, 32(4), pp. 327-336, 2012.

[12] Gottdiener, M., Budd, L. \& Lehtovuori, P., Key concepts in urban studies, Sage, 2015.

[13] Weisman, J., Evaluating architectural legibility way-finding in the built environment. Environment and behavior, 13(2), pp. 189-204, 1981. 
[14] Li, R. and Klippel, A., Wayfinding Behaviors in Complex Buildings The Impact of Environmental Legibility and Familiarity. Environment and Behavior, 2014. 0013916514550243.

[15] Hidayetoglu, M.L., Yildirim, K. \& Akalin, A., The effects of color and light on indoor wayfinding and the evaluation of the perceived environment. Journal of environmental psychology, 32(1), pp. 50-58, 2012.

[16] Long, Y. \& Baran, P.K., Does intelligibility affect place legibility? Understanding the relationship between objective and subjective evaluations of the urban environment. Environment and Behavior, 44(5), pp. 616-640, 2012.

[17] Hund, A.M., Visuospatial working memory facilitates indoor wayfinding and direction giving. Journal of Environmental Psychology, 2016.

[18] Mehta, V., Evaluating public space. Journal of Urban Design, 19(1), pp. 53-88, 2014.

[19] Rad, V.B., Najafpour, H., Ngah, I., Shieh, E. \& Rad, H.B., The Systematic Review on Physical Activity in Urban Neighborhoods. Life Science Journal, 11(9), 2014.

[20] Conroy-Dalton, R. \& Bafna, S., The syntactical image of the city: A reciprocal definition of spatial elements and spatial syntaxes, 2003.

[21] McIntyre, L., The way-finding journey within a large public building: a user centred study of the holistic way-finding experience across a range of visual ability (Doctoral dissertation, University of Dundee), 2011.

[22] Gibson, J.J., The Ecological Approach to Visual Perception, Psychology Press, 1986.

[23] http://www.locwsinternational.com/?tag=paul-granjon

[24] http://www.panoramio.com/photo/20073930

[25] McIntyre, L., The way-finding journey within a large public building: a user centred study of the holistic way-finding experience across a range of visual ability (Doctoral dissertation, University of Dundee), 2011. 